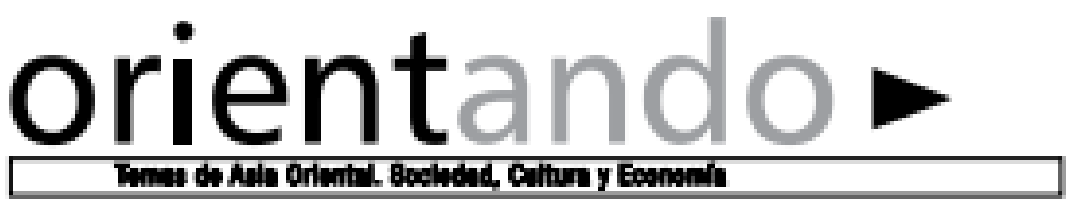

Año 10. Número 21. Octubre 2020-Marzo 2021

ISSN 2007-5723

Centro de Estudios China-Veracruz/Universidad Veracruzana

\title{
Difusión de la cultura china en América Latina y el Caribe (ALC). Retos y oportunidades
}

\section{Liu Jun ${ }^{1}$}

\section{Resumen:}

La relación comercial y económica entre China y América Latina y el Caribe (ALC) se ha incrementado de manera acelerada durante los últimos 20 años, esta situación influyó en que los intercambios aumentaran también en otros campos como la educación, el turismo y la ciencia y la tecnología. Sin embargo, las diferencias culturales y el desconocimiento entre China y ALC son algunos de los elementos que pueden convertirse en obstáculos para el desarrollo de la relación. Para China la difusión de su cultura resulta un factor fundamental para generar mejor imagen e intensificar el conocimiento mutuo con los países de ALC. En este trabajo se analiza la situación actual de la relación, se indican las diferencias entre culturas y se utiliza un modelo basado en las dimensiones culturales de Hofstede, para, a través de una perspectiva intercultural, definir algunos de los aspectos que China debe investigar y comprender en búsqueda de incrementar el poder blando y la difusión de la cultura china en los países de ALC.

Palabras clave: China, ALC relación, perspectiva intercultural, difusión, poder blando, cultura china.

\footnotetext{
${ }^{1}$ Profesora asociada de la Academia Nacional de Artes Teatrales de China, Decana adjunta del Departamento de Comunicación Cultural Internacional de NACTA.
} 


\begin{abstract}
:
The commercial and economic relationship between China and Latin America and the Caribbean (LAC) has increased rapidly during the last 20 years, this situation influenced the fact that exchanges also increased in other fields such as education, tourism and science and technology. However, the cultural differences and incomprehension between China and LAC are some of the elements that can become obstacles to the development of the relationship. For China, the diffusion of its culture is a fundamental factor to generate a better image and intensify mutual knowledge with the countries of LAC. In this work, the current situation of the cultural exchange relationship is analyzed, the differences between cultures are indicated and a model based on Hofstede's cultural dimensions is used, in order to define some of the aspects that China should, through an intercultural perspective research and understand in order to increase the soft power and diffusion of chinese culture in LAC countries.
\end{abstract}

Keywords: China, LAC, relationship, intercultural perspective, diffusion, soft power, Chinese culture.

\title{
1. Introducción y antecedentes históricos
}

El intercambio entre China y América Latina y el Caribe (ALC), tiene una larga historia, la Nao de China entre 1565 y 1815 unió ambas regiones, no solo en el intercambio comercial (seda, porcelana, plata, artes y alimentos, entre otros productos) sino también como un fuerte vínculo cultural y de intercambio de personas. Ambas regiones tienen una profunda influencia de esa comunicación histórica.

Desde la década de 1960, muchos países de ALC han establecido relaciones diplomáticas con China. En los últimos años, las relaciones económicas y comerciales entre ambas regiones han crecido exponencialmente. Sin embargo, ese crecimiento no ha generado el entendimiento cultural profundo, que es un elemento primordial para generar cambios profundos en todos los niveles de la relación.

Orientando. Temas de Asia Oriental. Sociedad, Cultura y Economía. Revista editada por el Centro de Estudios China-Veracruz de la Universidad Veracruzana, México (Centro de Estudios APEC) / año 10 / número 21/ 
Desde 2001, China se ha transformado en el primer o segundo socio comercial más importante de la mayoría de los países de ALC. Muchas empresas privadas y estatales chinas invierten en la región, sin embargo, ALC exporta principalmente materias primas a China, mientras que China exporta a ALC bienes y servicios con valor agregado. Esta situación, entre otras razones, ha generado serios desequilibrios en la balanza comercial entre ambas regiones.

En 2016 se realizó el año del intercambio cultural entre China y América Latina. Es fundamental analizar si la forma de comunicación de la cultura china ha ayudado efectivamente en este entendimiento mutuo. En pocos años países de ALC como República Dominicana, Panamá y El Salvador, se han establecido relaciones diplomáticas con China. Otros países (Costa Rica, Chile y Perú) avanzaron a un siguiente paso, firmando tratados de libre comercio. Y de hecho, 19 países de ALC han firmado el memorando de la Iniciativa de la Franja y la Ruta (IFR). Aunque los países de la región y China han ido aumentando la inversión y el comercio bilateral, la imagen positiva de China no ha mejorado en muchos de estos países, y parte de la población tampoco tiene un marcado interés en la cultura china.

Como indica Guo Cunhai (2017):

La gran distancia física entre China y ALC supone un alto costo de comunicación, constituyendo una enorme limitación para el intercambio cultural. Durante un plazo bastante largo desde la fundación de la nueva China, el intercambio cultural entre China y ALC ha sido poco activo y el contenido de interacción, muy limitado. Desde el nuevo siglo, sobre todo a partir de 2013, el intercambio cultural se ha convertido en un tema candente en la relación entre las dos partes. La aparición de este fenómeno es determinada por una serie de factores, pero sobre todo se debe a la condición objetiva, que es el desarrollo rápido de la relación integral entre China y ALC. (p. 200)

El presidente Xi Jinping ha prometido promover el poder blando cultural de China mediante la difusión de los valores chinos modernos y mostrando el encanto de la cultura china al mundo. Se necesitan esfuerzos para construir la imagen nacional de China, y debe Orientando. Temas de Asia Oriental. Sociedad, Cultura y Economía. Revista editada por el Centro de Estudios China-Veracruz de la Universidad Veracruzana, México (Centro de Estudios APEC) / año 10 / número 21/ 
ser retratada como un país civilizado con una rica historia, unidad étnica y diversidad cultural, y como una potencia oriental con buen gobierno, economía desarrollada, prosperidad cultural, unidad nacional y hermosas montañas y ríos. (China Daily, 24 de enero de 2014).

La cooperación entre la academia y el gobierno se ha fortalecido, pero para muchos ciudadanos de ALC, China sigue siendo un lugar desconocido y su comprensión sobre muchos aspectos de la cultura china aún es limitada.

La situación actual de la difusión de la cultura china en ALC debe analizarse desde diferentes factores, partiendo de la comprensión del concepto de cultura y algunos aspectos como la distancia geográfica, la distancia cultural, el papel de los medios de comunicación, y la complejidad del aprendizaje del idioma, la historia y la tradición china.

Kroeber y Kluckhohn (1952) identificaron más de 160 definiciones diferentes de cultura. Una de las primeras definiciones ampliamente citadas por Tylor (1871) define la cultura como "ese todo complejo que incluye el conocimiento, las creencias, el arte, la moral, la ley, la costumbre y cualquier otra capacidad y hábito adquiridos por el hombre como miembro de la sociedad". Entre los modelos que se utilizan para analizar las diferencias culturales, se selecciona el modelo de las seis dimensiones culturales de Hofstede, considerando que es el más adecuado para los fines de la investigación, teniendo en cuenta las diferencias y similitudes qué se deducen en ambas regiones a través de los datos obtenidos.

Debido a que los sistemas de valores juegan un papel importante cuando se habla de cultura, es necesario encontrar un método para observarlos. Geert Hofstede realizó una investigación que intentó clasificar las culturas nacionales en términos de amplias diferencias de valor en el lugar de trabajo entre 1967 y 1978. En esta investigación, realizada con 116, 000 empleados de 50 países y tres regiones dentro de una sola organización, IBM, Hofstede identificó cuatro dimensiones de la cultura nacional (Hofstede, 1984). Las dos últimas dimensiones se encontraron más tarde en la década de 1980. Las seis dimensiones son las siguientes: Distancia al poder; Individualismo; Aversión Orientando. Temas de Asia Oriental. Sociedad, Cultura y Economía. Revista editada por el Centro de Estudios 
a la incertidumbre; Masculinidad; Orientación a largo plazo e Indulgencia. Estas dimensiones son cuantificables en puntuaciones de 1 a 100.

\section{Raíces de la cultura tradicional china y elementos principales de la cultura china moderna}

China es un país con una superficie de 9.6 millones de kilómetros cuadrados, que ocupa el $6.5 \%$ del total mundial en donde habitan cerca de 1, 400 millones de personas, lo que representa aproximadamente una quinta parte de la población mundial y aumenta continuamente en unos 15 millones cada año. La población se puede dividir en 56 grupos étnicos, destacando la etnia Han que constituye más del $90 \%$ de la población. Hay más de 80 lenguas reconocidas, existiendo grandes diferencias en términos de dimensiones políticas, sociales y económicas entre China continental y lugares, como Hong Kong, Taiwán y Macao. Incluso estas diferencias se encuentran en China continental, debido a la ubicación geográfica, las condiciones naturales y el ritmo de desarrollo económico, sin embargo, se puede encontrar cierto grado de homogeneidad cultural en China, debido a que todo el país comparte algunos elementos comunes que ayudan a dar forma a la cultura nacional. Esto significa que muchos de los valores centrales del pueblo chino son únicos y consistentes, y se puede analizar a China continental considerándola como un todo homogéneo.

China es una de las civilizaciones más antiguas del mundo con una cultura profunda, duradera y con grandes periodos de desarrollo económico y social a lo largo de su historia.

\subsection{Confucianismo}

El confucianismo es un sistema ético y filosófico chino desarrollado a partir del filósofo chino Confucio (551-479 a.C.). Desde la dinastía Han, el confucianismo se ha convertido en la ideología oficial de doctrinas conductuales y morales con respecto a las relaciones

Orientando. Temas de Asia Oriental. Sociedad, Cultura y Economía. Revista editada por el Centro de Estudios China-Veracruz de la Universidad Veracruzana, México (Centro de Estudios APEC) / año 10 / número 21/ 
humanas, las estructuras sociales y el comportamiento virtuoso. El núcleo del confucianismo es el humanismo. Es famoso por sus cinco virtudes constantes: benevolencia, equidad, sabiduría, piedad filial y sinceridad. El confucianismo valora la importancia de la piedad familiar y filial, la estructura jerárquica de la vida social y el cultivo de la responsabilidad moral. Promueve la moderación y el énfasis en el trabajo duro.

\subsection{Taoísmo}

El taoísmo se originó en el siglo VI a. C., con el concepto básico de establecer armonía con el Tao, que significa "camino", o "principio", que se refiere al mecanismo de todo lo que existe. El concepto central de el taoísmo es “wu wei” (“acción sin acción”). Afirma que uno debe poner su voluntad en armonía con el universo, para encontrar la manera natural de hacer las cosas con el menor esfuerzo y el mayor éxito. Una necesidad taoísta es aprender observando el camino de la naturaleza y dejar que este lo guíe a través de la vida. El taoísmo valora la compasión, la moderación y la humildad, que significan amor y misericordia, moderación y modestia. Es considerado un estilo de vida.

\subsection{Budismo}

El budismo es una religión de mucha importancia en China. Se extendió al centro del país en el 67 d. C. durante la dinastía Han y ha tenido su época de prosperidad en los años siguientes. Su desarrollo, ha tenido una profunda influencia en las tradiciones, la cultura y el pensamiento chino, y se ha convertido en una de las religiones más importantes de la historia china y aparece en algunos de los aspectos de la vida moderna. A finales de la sociedad feudal, debido al malestar social, el budismo chino se desarrolló lentamente. Después de la fundación de la República Popular China y la implementación de la política de libertad en las creencias religiosas, adoptó su nueva era de crecimiento. El budismo indica que el bien será recompensado con el bien, y el mal, con el mal, y promueve que las personas realicen buenas obras. En su larga historia, el budismo chino, se entrelaza con el confucianismo y el taoísmo, configurando así la cultura tradicional china.

Orientando. Temas de Asia Oriental. Sociedad, Cultura y Economía. Revista editada por el Centro de Estudios China-Veracruz de la Universidad Veracruzana, México (Centro de Estudios APEC) / año 10 / número 21/ 


\subsection{Influencia de la cultura occidental en China}

Después de la Guerra del Opio, apareció otro factor importante que influye en la cultura china moderna, que es el de la cultura occidental. A finales de la dinastía Qing, el gobierno llevó a cabo el "Movimiento de occidentalización". En 1919, los intelectuales chinos lanzaron un nuevo movimiento cultural. Fue la introducción de la cultura occidental en China, que trajo grandes desafíos e influencias en su momento. La idea de igualdad, libertad, democracia y ciencia despertó grandes repercusiones y contradicciones con el confucianismo, taoísmo y budismo. La segunda corriente de apreciación de la cultura occidental en China fue desde la década de 1980, seguida de la reforma y la política de apertura. La cultura occidental enfatiza la libertad y el éxito individual, en tanto la cultura tradicional china promueve el colectivismo y armonía. Por un lado, la nueva cultura y las nuevas ideas también han traído consigo aportes al desarrollo social. La cultura china abraza a la cultura occidental generando la integración de la China moderna.

\subsection{Influencia del marxismo en China}

La filosofía marxista difiere de la cultura tradicional china en la jerarquía de las relaciones sociales. El gobierno promovió la ideología igualitaria para luchar contra el feudalismo y el culto jerárquico. La gente fue alentada por el espíritu revolucionario, entrando en conflicto directo con algunos aspectos de la cultura tradicional china. Por otro lado, el marxismo fomenta la propiedad común, el énfasis en el bienestar del país. De esta manera, las personas se atan aún más al grupo o comunidad a la que pertenecen, lo que indica un mayor colectivismo según el índice de dimensión cultural de Hofstede. Muchos estudiosos creen que el marxismo mucho más que cualquier otra filosofía o escuela de pensamiento, ha influido en la historia moderna de China. El marxismo, incorporado al espíritu nacional chino, se convirtió en una de las partes más importantes de la China moderna.

\subsection{Cultura china moderna}

La cultura y el estilo de vida occidental, así como la filosofía marxista, han influido en la sociedad china y generado un encuentro entre la cultura china moderna y la tradicional. La Orientando. Temas de Asia Oriental. Sociedad, Cultura y Economía. Revista editada por el Centro de Estudios China-Veracruz de la Universidad Veracruzana, México (Centro de Estudios APEC) / año 10 / número 21/ 
cultura china es una integración del confucianismo, el taoísmo, el budismo y la cultura occidental, así como el marxismo. Puede presentar algunas contradicciones en cierto modo, pero sin embargo, estas son las raíces de la cultura nacional china. Según la investigación de Hofstede, la cultura china posee una alta distancia de poder que es enfatizada por el confucianismo, y colectivismo (marxismo), masculinidad, evasión de baja incertidumbre (taoísmo), orientación a largo plazo (confucianismo y budismo) y baja indulgencia.

\section{Una clasificación de la cultura china basada en el modelo de dimensión de Hofstede}

Al explorar la cultura china a través de las seis dimensiones, el estudio de Hofstede muestra los índices más significativos que la cultura china valora. Este modelo resulta de fácil aplicación para poder profundizar en algunos de los factores que se pueden mejorar en la comunicación y el entendimiento entre ambas regiones.

\subsection{China: Distancia al poder}

Con una puntuación de 80 en esta dimensión, China se encuentra entre las clasificaciones más altas, lo que significa una sociedad que cree que las desigualdades entre las personas son aceptables. La relación entre el subordinado y el superior tiende a ser polarizada. Las personas en China están influenciadas por la autoridad formal, y en general, son optimistas sobre la capacidad e iniciativa de los líderes.

\subsection{China: Individualismo}

Con una puntuación de 20 en esta dimensión, China es una cultura altamente colectivista en la que las personas actúan en interés del grupo y no necesariamente de ellos mismos. Las relaciones con los miembros de la familia y los colegas chinos son cooperativas, cercanas y unidas dentro de los grupos. Para la mayoría de los chinos, las relaciones personales prevalecen sobre la tarea y la organización.

Orientando. Temas de Asia Oriental. Sociedad, Cultura y Economía. Revista editada por el Centro de Estudios China-Veracruz de la Universidad Veracruzana, México (Centro de Estudios APEC) / año 10 / número 21/ 


\subsection{China: Masculinidad}

Con una puntuación de 66, China es una sociedad masculina, orientada e impulsada por el éxito. Esto significa que, por un lado, se define claramente el papel de la mujer y el hombre y, por otro lado, se enfatiza una preferencia por el logro y el éxito en la sociedad. Bajo esta filosofía, a muchas personas les gustaría sacrificar las prioridades familiares y de ocio para trabajar y lograr el éxito.

\subsection{China: Aversión a la incertidumbre}

China tiene una puntuación baja en esta dimensión con 30 puntos. Los chinos se sienten cómodos con la ambigüedad; el idioma chino está lleno de significados ambiguos que pueden ser difíciles de comprender para los occidentales. Parte de la cultura china es la adaptación. Las leyes y reglas pueden ser flexibles para adaptarse la situación actual y el pragmatismo es parte del pensamiento actual.

\subsection{China: Orientación a largo plazo}

China tiene una puntuación de 87 en esta dimensión, lo que significa que es una cultura muy pragmática. En las sociedades con una orientación pragmática, la gente cree que la verdad depende en gran medida de la situación, el contexto y el tiempo. Muestra una capacidad para adaptar las tradiciones fácilmente a las condiciones cambiantes y una fuerte propensión a ahorrar e invertir, teniendo perseverancia en el logro de resultados.

\subsection{China: Indulgencia}

China posee baja puntuación ( 24 puntos) en esta dimensión, a diferencia de las sociedades indulgentes, las sociedades restringidas no ponen mucho énfasis en el tiempo libre, teniendo la percepción de que sus acciones están restringidas por las normas sociales.

Orientando. Temas de Asia Oriental. Sociedad, Cultura y Economía. Revista editada por el Centro de Estudios China-Veracruz de la Universidad Veracruzana, México (Centro de Estudios APEC) / año 10 / número 21/ 


\section{Difusión de la cultura china en ALC}

La influencia de China en ALC está creciendo, la inversión, los productos y la influencia cultural china se expandirán en ALC, pero aún existe un gran número de diferencias y malentendidos en temas culturales, políticos, empresariales y sociales, que deben ser resueltos por el entendimiento mutuo y la buena comunicación. Según el Investigador Guo Cunhai (2017) los motivos subyacentes de esta situación se pueden resumir en cuatro puntos:

1) La percepción de América Latina en China afecta la percepción de China en América Latina; 2) el proceso de formación de la historia y la cultura de América Latina conduce a que los latinoamericanos adopten una actitud de duda y preocupación hacia todos los extranjeros; 3) la cultura latinoamericana -que se ha formado en medio del choque y de la fusión de diferentes culturas-, es esencialmente mixta, dominada por la influencia de la cultura occidental y es sustancialmente diferente de la china; 4) el hecho de que los medios de comunicación occidentales ejerzan una influencia predominante sobre los de América Latina y que la capacidad de difusión exterior de China no sea suficiente, conducen a que sea especialmente difícil la construcción de la imagen de China en América Latina. (pp.11-12)

Aún muchos latinoamericanos no conocen a fondo los cambios tecnológicos y sociales que se han producido en China en los últimos 30 años. ¿Cómo conoce ALC a China?

a) Influencia de los inmigrantes chinos en ALC

b) La influencia de los medios latinoamericanos en la imagen china

c) Desempeño de empresas chinas en Latinoamérica

d) Intercambio de personas

\subsection{Influencia de los inmigrantes chinos en ALC}

Algunos países como Panamá, Perú, poseen cientos de años de inmigración china, que se pueden notar en la influencia en elementos culturales como la comida, música, artes, etc. En otros países como Argentina, la inmigración china ha sido muy fuerte en los últimos 20 años. Y en algunos países todavía la inmigración china no tiene una gran influencia, esto es muy importante cuando tratamos de determinar la influencia de las culturas chinas en diferentes países, donde la situación de la inmigración es diferente.

\subsection{La influencia de los medios de comunicación de ALC en la imagen de China}

Algunos de los medios de América Latina reproducen las noticias de las agencias internacionales, aún los medios chinos en ALC no son fuertes, y eso también determina que

Orientando. Temas de Asia Oriental. Sociedad, Cultura y Economía. Revista editada por el Centro de Estudios

China-Veracruz de la Universidad Veracruzana, México (Centro de Estudios APEC) / año 10 / número 21/

octubre 2020-marzo 2021 / ISSN: 2007-5723 
la imagen de China está moderada por opiniones de medios internacionales en muchos de los casos. Por otra parte, no son muchas las agencias o medios latinoamericanos que tienen base en China para obtener información directa, generándose dificultades para obtener datos originales de China.

\subsection{Empresas Chinas en ALC}

Muchas empresas chinas de energía e IT ingresaron al mercado de ALC en los últimos años, mientras que las de ingeniería y construcción, consideran que ALC puede ser un mercado emergente para el plan estratégico de largo plazo, con gran potencial y alta demanda. En 2019, hubo una encuesta realizada por la revista China Report en asociación con la Academia de Estudios Mundiales de China Contemporánea y la firma de investigación de mercado Kantar con sede en Londres. Un total de 2, 500 personas de cinco países latinoamericanos calificaron la imagen de las empresas chinas encuestadas cuyas líneas de negocio abarcan 13 sectores, incluidos energía, transporte, construcción, automóviles y electrodomésticos. La encuesta se basó en 133 empresas chinas que operan o venden productos allí. Las empresas chinas de Internet obtuvieron la mejor imagen entre los latinoamericanos encuestados, mientras que en segundo y tercer lugar en términos de calificación de imagen corporativa fueron la industria automotriz y las de productos para el hogar respectivamente. Los encuestados latinoamericanos dijeron que dan la bienvenida a las empresas chinas de tecnología avanzada, mostrando que un promedio del $51 \%$ espera cooperación en biotecnología y $49 \%$ en el sector de infraestructura, productos y servicios.

\subsection{Intercambio de personas}

El intercambio de personas ha ido creciendo durante los últimos años entre los países de ALC y China, pero aún es necesario mejorar para promover el entendimiento mutuo. Aunque algunos aspectos de una cultura pueden entenderse a través de la lectura, el arte y la comida, la comunicación humana sigue siendo la principal fuerza impulsora para comprender otra cultura. En este sentido, la promoción y el estímulo de los movimientos internacionales de personas, es parte importante del mutuo entendimiento, ya que tal convivencia entre países fortalece el programa de trabajo y la amistad entre China y ALC. Por tanto, la movilidad es la vía más profunda para promover un diálogo real entre civilizaciones.

La comunicación humana produce conocimientos difíciles de cuantificar, pero contribuye a las relaciones económicas, culturales y sociales, así como a la comprensión histórica entre campos relevantes. Como resultado, esta actividad contribuye a una mejor comprensión de cómo se coordinan las políticas, qué tipo de interconexiones se necesitan, mejorar la liquidez de los intercambios económicos y la comprensión de la integración financiera, convirtiéndose así en una variable intermedia en las interconexiones de todos los demás aspectos (Zottele, 2019).

Orientando. Temas de Asia Oriental. Sociedad, Cultura y Economía. Revista editada por el Centro de Estudios 


\subsection{Modelo de la Investigación}

Según la teoría de Hofstede, los países de América Latina tienen diferencias y similitudes con China en algunas dimensiones. Se debe entender la cultura no como un concepto total, sino como un concepto formado por diferentes dimensiones, esto permite comprender las similitudes y diferencias con China por país. Pudiendo fomentar el conocimiento a partir de las similitudes y desde esa zona confortable, poder superar la zona de complejidad a través del entendimiento de las diferencias (Gráfico 1).

\section{Gráfico 1. Difusión de la cultura china, desde las similitudes de las dimensiones culturales hasta las diferencias de las dimensiones culturales.}

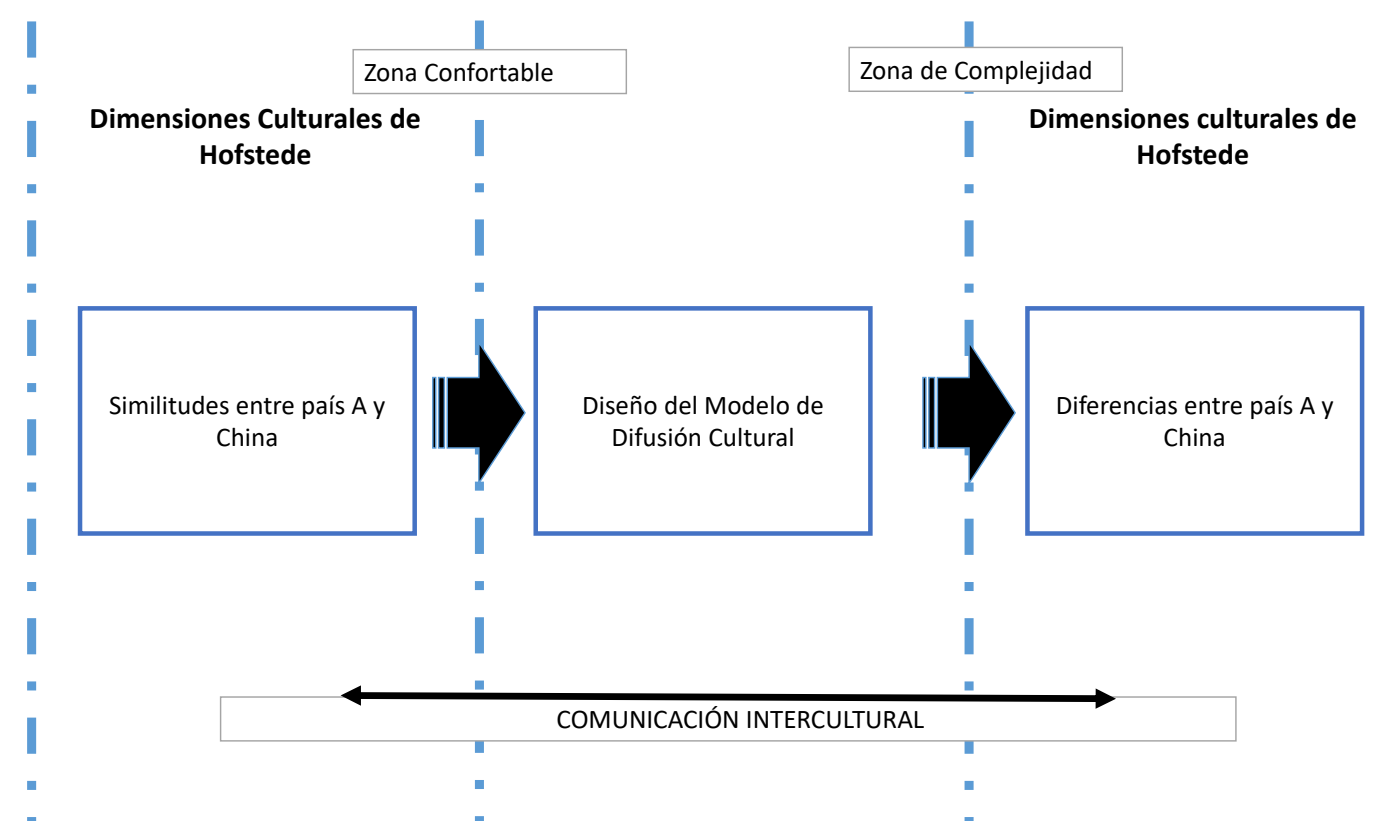

Fuente: Elaboración propia.

Orientando. Temas de Asia Oriental. Sociedad, Cultura y Economía. Revista editada por el Centro de Estudios China-Veracruz de la Universidad Veracruzana, México (Centro de Estudios APEC) / año 10 / número 21/ 


\section{Gráfico 2. Conjunción de la difusión de la cultura china desde diferentes dimensiones} culturales.

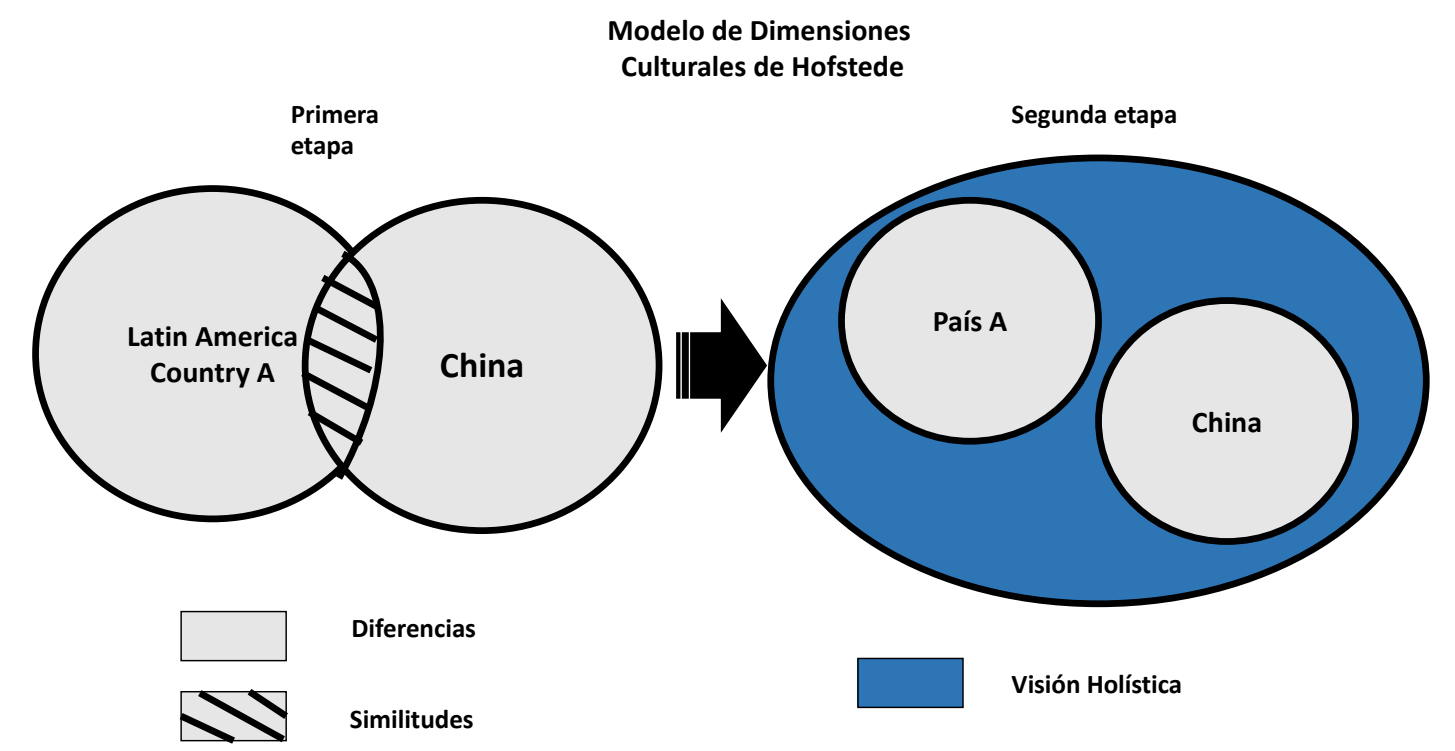

Fuente: Elaboración propia

Como primer paso, desde el punto de vista de China, se debe comprender de una manera más profunda la diferencia en las dimensiones culturales del país en donde se pretende difundir la cultura de una manera efectiva. El segundo paso debe tener una visión holística (Figura 2) y generar así, vías de comunicación intercultural para promover el entendimiento mutuo, fomentando la comunicación directa entre ambas regiones. Aunque por razones prácticas, nos hemos acostumbrado a reducir un tema de estudio a sus partes para poder comprenderlo, hay un riesgo de perder la visión por completo y si el enfoque es limitado, las verdaderas soluciones se vuelven esquivas. La visión holística permitirá hacer diferentes modelos de difusión de la cultura china en diferentes países. El entendimiento intercultural será un paso necesario para la comprensión de la cultura local, a través de la que se podrá difundir la cultura china de manera efectiva.

\section{Conclusiones e investigaciones futuras}

La comunicación cultural entre China y ALC, se remonta a finales del siglo XVI a través de la Nao de China. Desde la década de 1960, muchos países latinoamericanos han establecido relaciones diplomáticas con China y, en los últimos años, cada vez más países de ALC se Orientando. Temas de Asia Oriental. Sociedad, Cultura y Economía. Revista editada por el Centro de Estudios 
unen a la Iniciativa de la Franja y la Ruta. Esto ha llevado a un intercambio y cooperación más extensa y profunda entre las dos partes a nivel nacional, organizativo e interpersonal. Sin embargo, las diferencias culturales y el desconocimiento entre China y ALC siguen siendo factores que pueden convertirse en obstáculos para un mejor desarrollo de la relación. Según indica el modelo de las dimensiones culturales de Hofstede, las dos partes comparten algunas similitudes en elementos culturales, pero también tienen algunas diferencias. Es importante comprender las diferencias entre la cultura china y la de ALC, y como a través de las prácticas de comunicación intercultural promover la difusión de la cultura china. El punto clave es establecer una imagen real de la China moderna por parte de las personas, las organizaciones y los medios de comunicación de todas las partes involucradas en la comunicación intercultural. Basándose en el modelo de dimensiones culturales de Hofstede, este trabajo explica como a través del entendimiento de las diferencias y similitudes culturales, con la aplicación de una visión holística se puede diagramar la difusión de la Cultura China en ALC. De esta manera se encontrarán las vías de comunicación para tratar de evitar los malentendidos culturales y promover el entendimiento mutuo entre ambas regiones. El modelo requerirá de más desarrollo e investigación futura, con la necesidad de realizar encuestas, para comprender las diferencias culturales más profundamente.

\section{Referencias}

China Daily (24 de enero de 2014). China to promote cultural soft power. Obtenido de: http://www.chinadaily.com.cn/china/2014-01/01/content_17208354.htm

Collide, W. C. (1996). Managing Successfully Across Cultures. Nicholas Brealey, London.

Dimitrov, K. (2012). Natural analogies among organizational culture models. Vanguard scientific instruments in management, 5(1), 99-125.

England, G. W. (1978). Managers and their value systems: a five-country comparative study. Columbia Journal of World Business, 13(2), 35-44

Fan, Y. (2000). A classification of Chinese culture. 7; 2.

Orientando. Temas de Asia Oriental. Sociedad, Cultura y Economía. Revista editada por el Centro de Estudios China-Veracruz de la Universidad Veracruzana, México (Centro de Estudios APEC) / año 10 / número 21/ 
Ferraro, G.P. (1990). The Cultural dimensions of international business . Englewood Cliffs, NJ: Prentice Hall.

Guo C. H. (2017). La imagen de China en América Latina en el siglo XXI. Orientando Temas de Asia Oriental, Sociedad, Cultura y Economía, 14, 11-44.

Guo C. H. (2017). Intercambio Cultural: El Nuevo Pilar de la Relación entre China y ALC. Revista peruana de estudios del Asia-Pacífico, 199.

Hofstede, G. (1980), Culture's Consequences: International Differences in Work-Related Values, Beverly Hills CA: Sage Publications.

Hofstede, G. (1984). Cultural dimensions in management and planning, Asia Pacific

Journal of Management, 81-99

Hofstede, G. (2001), Culture's Consequences: Comparing Values, Behaviors, Institutions and Organizations Across Nations, 2nd Edition, Thousand Oaks CA: Sage Publications.

Kluckhohn, C. K. (1949). Mirror for man: the relation of anthropology to modern life. Berkeley, CA: Whittlesey House.

Kluckhohn, F. R., \& Strodtbeck, F. L. (1961). Variations in value orientations. Evanston, IL: Row, Peterson.

Kroeber, A. L., \& Kluckhohn, C. (1952). Culture: A critical review of concepts and definitions. Papers. Peabody Museum of Archaeology \& Ethnology, Harvard University.

Rokeach, J. (1973). The Nature of Human Values, the Free Press, NY.

Ronen, S., \& Shenkar, O. (1985). Clustering countries on attitudinal dimensions: A review and synthesis. Academy of management Review, 10(3), 435-454.

Schwartz, S. H. (1992). Universals in the content and structure of values: Theoretical advances and empirical tests in 20 countries, in M. Zanna (Ed.). Advances in experimental social psychology, pp. 1-65, New York: Academic Press.

Schwartz, S. H. (1999). A theory of cultural values and some implications for work, in Applied Psychology: An International Review, No. 48 (1), pp. 23-47. 106 New Management for the New Economy", November 7 y 8 2013, Bucharest, Romania.

Terpstra, V., \& David, K. (1991). The cultural environment of business. Cincinnati, OH: South-Western.

Trompenaars, F., \& Hampden-Turner, C. (1997). Riding the Waves of Culture: Understanding Cultural Diversity in Business, Second Edition, London \& Santa

Orientando. Temas de Asia Oriental. Sociedad, Cultura y Economía. Revista editada por el Centro de Estudios 
Rosa, Nicholas Brealey Publishing Limited.

Trompenaars, F., \& Woolliams, P. (2003). Business Across Cultures, Capstone Publishing Ltd.

Trompenaars, F., \& Hampden-Turner, C. (2004). Managing People Across Cultures, Capstone. Publishing Ltd. Project GLOBE (Global Leadership and Organizational Behavior Effectiveness).

Tylor, E. (1871). Origins of culture. Harper \& Row, NY.

Woods, P., Barker, M. C., \& Troth, A. (2008). A holistic definition of cross-cultural management performance. In 2008 IFSAM 9th World Congress: The Fusion and Development of East and West Management, Shanghai, 26-28 July.

Zottele. E. (2019). Intercambio de personas, base del entendimiento mutuo bajo el marco de la Iniciativa de La Franja y la Ruta en América Latina. Libro "Veracruz : De la Nao de China a la Franja y la Ruta". Centro de Estudios China-Veracruz.

Orientando. Temas de Asia Oriental. Sociedad, Cultura y Economía. Revista editada por el Centro de Estudios China-Veracruz de la Universidad Veracruzana, México (Centro de Estudios APEC) / año 10 / número 21/ 